\title{
INTEGRITAS KEPEMIMPINAN KEPALA SEKOLAH DAN BUDAYA ORGANISASI SERTA PENGARUHNYA TERHADAP EFEKTIVITAS KERJA GURU
}

\author{
Areagama \\ SMP N 1 Cantigi, Jl. Raya, Cantigi Kulon Indramayu, Jawa Barat- Indonesia, \\ areagama2@gmail.com
}

Received April 27, 2018, reviewed Juni 30, 2018, published September 30, 2018

Citation: Areagama (2018). Integritas Kepemimpinan Kepala Sekolah dan Budaya Organisasi Serta Pengaruhnya terhadap Efektivitas Kerja Guru. Edum Journal, Vol 1, No 2, Hal 76-89, September 2018.

DOI: https://doi.org/10.31943/edumjournal.v1i2.476

\begin{abstract}
ABSTRAK
Fokus penelitian ini bertujuan untuk mengetahui integrasi kepemimpinan kepala sekolah dan budaya organisasi sekolah serta pengaruhnya terhadap efektivitas kerja guru. Metode penelitian yang digunakan adalah metode survey dengan cara menyebarkan angket kepada 104 responden. Pengambilan sampel menggunanakan teknik Cluster Random Sampling. Data yang diperoleh dari hasil penelitian diolah menggunakan analisis statistik, deskriptif dilengkapi dengan analisis regresi sederhana dan regresi ganda. Hasil penelitian menunjukkan bahwa: (1) Terdapat pengaruh positif dan signifikan integritas kepemimpinan kepala sekolah terhadap efektivitas kerja guru. (2) Terdapat pengaruh positif dan signifikan budaya organisasi sekolah terhadap efektivitas kerja guru. (3) Terdapat pengaruh positif dan signifikan integritas kepemimpinan kepala sekolah dan budaya organisasi sekolah secara simultan terhadap efektitivitas kerja guru. Beranjak dari kondisi yang ada, penulis menyarankan: (1) Dalam rangka meningkatkan integritas kepemimpinannya, kepala sekolah perlu meningkatkan keterpaduan dalam memimpin serta lebih transparan dalam mengelola sekolah melalui komunikasi rutin dengan guru sebagai mitra kerjanya. (2) Budaya organisasi sekolah juga merupakan salah satu yang dapat meningkatkan efektivitas kerja guru. Untuk itu, kepala sekolah perlu meningkatkan toleransi terhadap tindakan berisiko dan toleransi terhadap konflik dengan cara membangun pola komunikasi yang lebih mudah dipahami oleh semua elemen di sekolah.
\end{abstract}

Kata Kunci: Integritas Kepemimpinan, Budaya Organisasi Sekolah, Efektivitas Kerja

\section{ABSTRACT}

The focus of this study aims to determine the integration of principals' leadership and school organizational culture as well as their influence on teacher work effectiveness. The research method used was the survey method by distributing questionnaires to 104 respondents. Sampling uses cluster random sampling techniques. Data obtained from the results of the study were processed using statistical analysis, descriptive equipped with simple regression analysis and multiple regression. The results of the study show that: (1) There is a positive and significant influence on the leadership integrity of the principal towards the work effectiveness of the teacher. (2) There is a positive and significant influence of school organizational culture on teacher work effectiveness. (3) There is a positive and significant influence of principals' leadership integrity and school organizational culture simultaneously on the effectiveness of teacher work. Moving on from the existing conditions, the authors suggest: (1) In order to improve leadership integrity, school principals need to improve cohesiveness in leading and more transparent in managing schools through regular communication with teachers as their partners. (2) School organizational culture is also one that can improve teacher work effectiveness. For this reason, principals need to increase tolerance for risky actions and tolerance for conflict by building communication patterns that are more easily understood by all elements in the school.

Keywords: Leadership Integrity, School Organizational Culture, Work Effectiveness 
PENDAHULUAN

Efektivitas kerja guru tergambar dari penampilan dan kinerja guru (Siti Asiah. T, 2016). Menjadi guru artinya mampu mengelola pengajaran di dalam kelas dan mendidik siswa diluar kelas dengan sebaikbaiknya, memiliki loyalitas yang tinggi pada tugas mengajar, menguasai dan mengembangkan metode mengajar, menguasasi bahan pelajaran dan menggunakan sumber belajar, bertanggungjawab memantau hasil belajar mengajar, kedisiplinan dalam mengajar dan tugas lainnya, kreativitas dalam pelaksanaan pengajaran, melakukan interaksi dengan siswa untuk menimbulkan motivasi, kepribadian yang baik dan obyektif dalam membimbing siswa, guru mampu berpikir sistematis tentang apa yang dilakukannya, dan pemahaman dalam administrasi pengajaran (Suwardi1, Masni Erika Firmiana2, Fitrin Nida, 2015).

Untuk mendukung efektivitas guru dalam situasi dan kondisi seperti ini diperlukan banyak faktor, baik yang berasal dari dirinya sendiri maupun dari luar dirinya, seperti adanya motivasi berprestasi guru, kepala sekolah yang memiliki kemampuan untuk mengarahkan, menggerakkan, memotivasi dan mengendalikan juga mengawasi segala kebutuhan guru, serta dapat menciptakan iklim dan organisasi sekolah yang menyenangkan sehingga guru-guru memiliki gairah untuk mengembangkan kinerja dalam menujang prestasi kerjanya (I Made Subawa, Anak Agung Gede Agung, I Made Yudana, 2015).

Kinerja guru dipengaruhi oleh berbagai faktor. Adapaun faktor-faktor tersebut di antaranya kompetensi guru, profesionalisme, integritas, supervisi pengajaran, program pengembangan keterampilan guru, iklim sekolah, sarana dan prasarana, kondisi fisik dan mental guru, gaya kepemimpinan kepala sekolah, jaminan kesejahteraan, efektivitas manajemen sekolah, dan lain-lain. Faktor individu guru juga sangat penting, karena sebaik apapun kurikulum, jika tidak dibarengi oleh guru yang berkualitas, maka semuanya akan sia-sia (Mulyasa, 2005: 147).

Integritas dan profesionalisme sebagai faktor individu menjadi sangat penting dalam mewujudkan kinerja guru yang optimal. Integritas merupakan salah satu pilar yang diyakni manusia dalam membentuk perilaku. Kepala sekolah yang memiliki integritas tercermin dari perilaku kinerjannya. Cloud (2006: 31) menyatakan bahwa integritas adalah kualitas untuk berlaku jujur, dapat dipercaya, tulus, dan bersikap tegas. Setiap orang memerlukan 
integritas dalam mewujudkan kinerja, sebagaimana dinyatakan oleh Baysari (2013: 133) bahwa integritas berpengaruh positif dan signifikan terhadap kinerja guru. Berdasarkan hasil penelitian Wulandari (2014) dapat disimpulkan bahwa ada pengaruh antara Budaya Organisasi terhadap Kinerja Guru Di SMK Negeri 2 Ngawi Tahun 2014. Selain itu berdasarkan hasil penelitian nurul fitriah (2018) menyimpulkan Hasil penelitian ini menunjukkan bahwa secara parsial budaya organisasi, lingkungan kerja dan kedisiplinan tidak memiliki pengaruh yang signifikan terhadap kinerja guru, sedangkan secara simultan budaya organisasi, lingkungan kerja dan kedisiplinan memiliki pengaruh yang signifikan terhadap kinerja guru SMP Negeri 2 Sungai Ambawang. Hal lain berdasarkan hasil penelitian Beni Habibi (2013) menyimpulkan bahwa jika budaya organisasi sekolah semakin baik, kompensasi semakin baik atau memadai, dan kompetensi pedagogik semakin baik maka kinerja guru meningkat.

Berdasarkan paparan diatas harus dilihat seberapa besar pengaruh faktor integritas kepala sekolah, guru dan tenaga pendidikan dan budaya organisasi antar masyarakat sekolah terhadap efektifiktas kerja guru di sekolah.

\section{METODE PENELITIAN}

Metode penelitian yang digunakan dalam penelitian ini yakni metode survey dengan pendekatan kuantitatif dengan melakukan studi eksplorasi dan konfirmasi pada guru SMP Negeri di Sektor I Kabupaten Indramayu. Sedangkan jumlah populasi ada 692 orang dan mengambil sampel dengan mengacu pada pendapat Arikunto (2007:116) yang menyatakan bahwa "penelitian dapat dilakukan apabila populasi benar homogen. Oleh karenanya, pada penelitian ini ditentukan sampel sebanyak $15 \%$ atau 104 orang guru dengan teknik pengambilan simple random sampling. Teknik pengumpulan data dengan menyebarkan angket kepada responden. Angket yang disebarkan telah melalui uji validitas dan reliabilitas. Untuk memudahkan penysunan angket dibuat kisikisi sebagai berikut: 
Tabel 1 Kisi-kisi Instrumen Variabel Integritas Kepemimpinan

\begin{tabular}{llll} 
No. & Dimensi & \multicolumn{1}{c}{ Indikator } \\
\hline 1 & Jujur & a. Menumbuhkan kepercayaan \\
& & b. Menumbuhkan motivasi \\
& & c. Menumbuhkan inovasi \\
& & d. Menumbuhkan kreatifitas \\
2 & \multirow{3}{*}{ Kredibel } & a. Kekerabatan \\
& & b. Menjadi figur bagi guru \\
& & c. Keselarasan antara kata dan perbuatan \\
& \multirow{3}{*}{ Transparan } & d. Membangun koordinasi \\
& & e. Konsisten \\
& & f. Memberi kesempatan mengemukakan \\
& & g. & ide \\
& & &
\end{tabular}

Tabel 2 Kisi-kisi Instrumen Variabel Budaya Organisasi

\begin{tabular}{|c|c|c|}
\hline$\overline{\text { No }}$ & Dimensi & Indikator \\
\hline 1 & Inisiatif Individual & $\begin{array}{l}\text { a. Tanggung jawab } \\
\text { b. Independensi }\end{array}$ \\
\hline 2 & $\begin{array}{l}\text { Toleransi terhadap } \\
\text { tindakan beresiko }\end{array}$ & $\begin{array}{l}\text { c. Bertindak agresif } \\
\text { d. Berani mengambil risiko }\end{array}$ \\
\hline 3 & Pengarahan & $\begin{array}{l}\text { e. Menentukan visi } \\
\text { f. Menciptakan sasaran dan harapan }\end{array}$ \\
\hline 4 & Integritas & $\begin{array}{l}\text { g. Kerjasama } \\
\text { h. Kekompakan }\end{array}$ \\
\hline 5 & $\begin{array}{l}\text { Dukungan } \\
\text { manajemen }\end{array}$ & $\begin{array}{ll}\text { i. } & \text { Komunikasi } \\
\text { j. } & \text { Membantu kelancaran }\end{array}$ \\
\hline 6 & Kontrol alat & k. Pengawasan \\
\hline 7 & Identitas & $\begin{array}{l}\text { 1. Mengidentifikasi diri sebagai satu } \\
\text { kesatuan }\end{array}$ \\
\hline 8 & Sistem imbalan & $\begin{array}{l}\text { m. Gaji } \\
\text { n. Promosi }\end{array}$ \\
\hline 10 & $\begin{array}{l}\text { Toleransi. Toleransi } \\
\text { terhadap konflik } \\
\text { Pola komunikasi }\end{array}$ & $\begin{array}{l}\text { o. Mengemukakan kritik secara terbuka } \\
\text { p. Mengadakan perubahan } \\
\text { q. Hierarki kewenangan }\end{array}$ \\
\hline \multicolumn{3}{|c|}{$\begin{array}{c}\text { Robbins (2006) } \\
\text { Tabel } 3 \text { Kisi-kisi Instrumen Variabel Efektivitas Kerja Guru }\end{array}$} \\
\hline No. & Dimensi & Indikator \\
\hline 1 & $\begin{array}{l}\text { Kemampuan menyesua } \\
\text { diri }\end{array}$ & $\begin{array}{ll}\text { a. } & \text { Kerjasama } \\
\text { b. } & \text { Tanggungjawab }\end{array}$ \\
\hline 2 & Kepuasan kerja & $\begin{array}{l}\text { c. Puas atas penghasilan/gaji } \\
\text { d. Adanya penghargaan/aktualisasi } \\
\text { kerja } \\
\text { e. Situasi kerja }\end{array}$ \\
\hline 3 & Prestasi kerja & $\begin{array}{ll}\text { f. Motivasi kerja } \\
\text { g. Hasil Karya }\end{array}$ \\
\hline
\end{tabular}

Richard M. Steers (1982) 
HASIL PENELITIAN DAN sekolah $\left(\mathrm{X}_{1}\right)$ terhadap efektivitas kerja guru PEMBAHASAN

(Y) dilakukan dengan uji regresi linear

Fokus utama pada penelitian ini adalah dengan menggunakan software SPSS versi untuk mengetahui besaran pengaruh 23. integritas kepemimpinan kepala sekolah

Untuk mengetahui besaran pengaruh dan budaya organisasi terhadap efektivitas integritas kepemimpinan kepala sekolah kerja guru baik secara parsial mapun ganda. $\left(\mathrm{X}_{1}\right)$ secara individual (parsial) terhadap Pengaruh Integritas Kepemimpinan efektivitas kerja guru (Y) dapat dilihat dari Kepala Sekolah Terhadap Efektivitas Kerja Guru

Untuk mengetahui besaran pengaruh nilai t pada tabel Coeffiients dibawah ini dengan kriteria pengujian jika tingkat signifikansi lebih kecil dari 0,05. variabel integritas kepemimpinan kepala

Tabel 4: Koefisien Persamaan Regresi Variabel Xı terhadap Y Coefficients $^{\mathrm{a}}$

\begin{tabular}{|c|c|c|c|c|c|c|}
\hline \multirow[b]{2}{*}{ Model } & & \multicolumn{2}{|c|}{$\begin{array}{c}\text { Unstandardized } \\
\text { Coefficients }\end{array}$} & \multirow{2}{*}{$\begin{array}{c}\text { Standardized } \\
\text { Coefficients } \\
\text { Beta }\end{array}$} & \multirow[b]{2}{*}{$\mathrm{t}$} & \multirow[b]{2}{*}{ Sig. } \\
\hline & & B & Std. Error & & & \\
\hline \multirow[t]{2}{*}{1} & (Constant) & 38,888 & 11,774 & & 3,303 & ,001 \\
\hline & Integritas_Kepemimpinan_ $\mathrm{X}_{1}$ & ,832 &, 174 & ,427 & 4,768 &, 000 \\
\hline
\end{tabular}

a. Dependent Variable: Efektivitas_Kerja_Guru_Y

Berdasarkan tabel hasil uji t diperoleh bahwa nilai $t_{\text {hitung }}$ variabel integritas kepemimpinan kepala sekolah $\left(\mathrm{X}_{1}\right)$ memiliki nilai sebesar $p$-value $0,000<0,05$ artinya berdistribusi signifikan. Hal tersebut berarti integritas kepemimpinan kepala sekolah $\left(\mathrm{X}_{1}\right)$ secara parsial berpengaruh terhadap efektivitas kerja guru (Y). Persamaan regresi $\hat{y}=a b_{1}$ dari hasil perhitungan diperoleh $\hat{y}=38,888+$ $0,832 \mathrm{X}_{1}$. Konstanta sebesar 38,888 menyatakan bahwa jika ada kenaikan nilai dari variabel integritas kepemimpinan kepala sekolah $\left(\mathrm{X}_{1}\right)$, maka efektivitas kerja guru (Y) adalah 38,888. Koefesien regresi sebesar 0,832 menyatakan bahwa setiap perubahan satu skor atau nilai integritas kepemimpinan kepala sekolah akan memberikan skor 0,832 .

Uji $F$ untuk menguji signifikansi konstanta dan variabel dependen (efektivitas kerja guru). Dari pengambilan keputusan yaitu dengan membandingkan $\mathrm{F}$ hitung dengan nilai $\mathrm{F}$ tabel sebagai berikut: 
jika nilai signifikansi $<0,05$, maka Ho dan sebaliknya.

ditolak artinya koefesien regresi signifikan,

Tabel 5: Signifikansi Pengaruh Variabel $X_{1}$ terhadap $Y$

ANOVA $^{\mathrm{a}}$

\begin{tabular}{|cl|r|r|r|r|r|}
\hline Model & & Sum of Squares & df & Mean Square & F & Sig. \\
\hline \multirow{2}{*}{1} & Regression & 2847,187 & 1 & 2847,187 & 22,730 &, $000^{\mathrm{b}}$ \\
& Residual & 12776,727 & 102 & 125,262 & & \\
& Total & 15623,913 & 103 & & & \\
\hline
\end{tabular}

a. Dependent Variable: Efektivitas_Kerja_Guru_Y

b. Predictors: (Constant), Integritas_Kepemimpinan_ $X_{1}$

Berdasarkan tabel hasil uji anova atau Selanjutnya untuk mengetahui seberapa

$\mathrm{F}$ test didapat $\mathrm{F}_{\text {hitung }}$ sebesar 22,730 dan besar pengaruh integritas kepemimpinan nilai signifikansi $0,000<0,05$. Dengan kepala sekolah terhadap efektivitas kerja demikian $\mathrm{H}_{\mathrm{o}}$ ditolak artinya pengaruh guru dapat dilihat dari hasil perhitungan integritas kepemimpinan kepala sekolah koefesien determinasi pada tabel dibawah terhadap efektivitas kerja guru adalah ini: signifikan.

Tabel 6: Besaran Pengaruh Variabel $X_{1}$ terhadap $Y$ Model Summary

\begin{tabular}{|c|r|r|r|c|}
\hline Model & R & R Square & \multicolumn{1}{|c|}{$\begin{array}{c}\text { Adjusted R } \\
\text { Square }\end{array}$} & $\begin{array}{c}\text { Std. Error of the } \\
\text { Estimate }\end{array}$ \\
\hline 1 &, $427^{\mathrm{a}}$ &, 182 &, 174 & 11,192 \\
\hline
\end{tabular}

a. Predictors: (Constant), Integritas_Kepemimpinan_X

Dari tabel di atas terlihat bahwa $R$ Square sebesar 0,182 , hal ini berarti bahwa 18,2\% efektivitas kerja guru dipengaruhi oleh variabel integritas kepemimpinan kepala sekolah, sedangkan sisanya 71,8 \% dipengaruhi oleh faktor lain yang tidak diteliti.

\section{Pengaruh Budaya Organisasi Terhadap} Efektivitas Kerja Guru

Untuk mengetahui besaran pengaruh budaya organisasi sekolah $\left(\mathrm{X}_{2}\right)$ secara individual (parsial) terhadap efektivitas kerja guru (Y) dapat dilihat dari nilai t pada tabel Coefficients dibawah ini dengan 
kriteria pengujian jika tingkat signifikansi lebih kecil dari 0,05.

Tabel 7: Koefisien Persamaan Regresi Variabel $X_{2}$ terhadap $Y$ Coefficients $^{\mathrm{a}}$

\begin{tabular}{|c|c|c|c|c|c|c|}
\hline \multirow[b]{2}{*}{ Model } & & \multicolumn{2}{|c|}{$\begin{array}{c}\text { Unstandardized } \\
\text { Coefficients }\end{array}$} & \multirow{2}{*}{$\begin{array}{c}\text { Standardized } \\
\text { Coefficients } \\
\text { Beta }\end{array}$} & \multirow[b]{2}{*}{ t } & \multirow[b]{2}{*}{ Sig. } \\
\hline & & B & Std. Error & & & \\
\hline 1 & (Constant) & 42,453 & 12,909 & & 3,289 &, 001 \\
\hline & Budaya_Organisasi_X ${ }_{2}$ &, 885 & ,218 & 374 & 4,069 &, 000 \\
\hline
\end{tabular}

a. Dependent Variable: Efektivitas_Kerja_Guru_Y

Berdasarkan tabel hasil uji t diperoleh $\quad\left(\mathrm{X}_{2}\right)$, maka efektivitas kerja guru $(\mathrm{Y})$ adalah

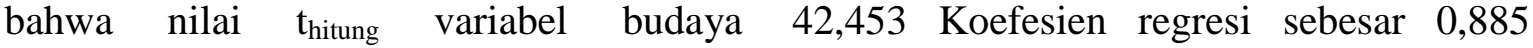
organisasi sekolah $\left(\mathrm{X}_{2}\right)$ memiliki nilai menyatakan bahwa setiap perubahan satu sebesar p-value $0,000<0,05$ artinya skor atau budaya organisasi sekolah akan signifikan. Dengan demikian budaya memberikan skor 0,885. Uji F untuk organisasi sekolah $\left(\mathrm{X}_{2}\right)$ secara parsial menguji signifikan konstanta dan variabel berpengaruh terhadap efektivitas kerja guru dependen (efektivitas kerja guru). Dari (Y). Persamaan regresi $\mathrm{y}=\mathrm{a} \mathrm{bx}_{2}$ dari hasil pengambilan keputusan yaitu dengan perhitungan diperoleh $\hat{y}=42,453+$ membandingkan $\mathrm{F}$ hitung dengan nilai $\mathrm{F}$ $0,885 \mathrm{X}_{2}$. Konstanta sebesar 42,453 tabel sebagai berikut: jika nilai signifikansi menyatakan bahwa jika ada kenaikan nilai < 0,05, maka Ho ditolak artinya koefesien dari variabel budaya organisasi sekolah regresi signifikan, dan sebaliknya.

Tabel 8: Signifikansi Pengaruh Variabel $X_{2}$ terhadap $Y$ ANOVA

\begin{tabular}{|c|c|c|c|c|c|c|}
\hline \multicolumn{2}{|c|}{ Model } & Sum of Squares & df & Mean Square & $\mathrm{F}$ & Sig. \\
\hline 1 & Regression & 2181,910 & 1 & 2181,910 & 16,557 &, $000^{\mathrm{b}}$ \\
\hline & Residual & 13442,004 & 102 & 131,784 & & \\
\hline & Total & 15623,913 & 103 & & & \\
\hline
\end{tabular}

a. Dependent Variable: Efektivitas_Kerja_Guru_Y

b. Predictors: (Constant), Budaya_Organisasi_X

Berdasarkan tabel hasil uji anova mengetahui seberapa besar pengaruh atau $\mathrm{F}$ test didapat $\mathrm{F}_{\text {hitung }}$ sebesar 16,557 budaya organisasi sekolah terhadap dan signifikansi $0,000<0,05$ sehingga $\mathrm{H}_{\mathrm{o}}$ efektivitas kerja guru dapat dilihat dari hasil ditolak artinya pengaruh budaya organisasi perhitungan koefesien determinasi pada sekolah terhadap efektivitas kerja guru tabel dibawah ini: adalah signifikan. Selanjutnya untuk 
Tabel 9: Besaran Pengaruh Variabel $X_{2}$ terhadap $Y$

Model Summary

\begin{tabular}{|c|r|r|r|c|}
\hline Model & \multicolumn{1}{|c|}{$\mathrm{R}$} & R Square & \multicolumn{1}{c|}{$\begin{array}{c}\text { Adjusted R } \\
\text { Square }\end{array}$} & $\begin{array}{l}\text { Std. Error of the } \\
\text { Estimate }\end{array}$ \\
\hline 1 &, $374^{\mathrm{a}}$ &, 140 &, 131 & 11,480 \\
\hline
\end{tabular}

a. Predictors: (Constant), Budaya_Organisasi_ $X_{2}$

Dari tabel di atas terlihat bahwa $R$

Untuk mengetahui besarnya

Square sebesar 0,140, hal ini berarti bahwa

$14 \%$ efektivitas kerja guru dipengaruhi

oleh variabel budaya organisasi sekolah, sedangkan sisanya $76 \%$ dipengaruhi oleh faktor lain yang tidak diteliti.

Pengaruh integritas kepemimpinan kepala sekolah dan budaya organisasi sekolah Terhadap Efektivitas Kerja

Guru

Tabel 10: Koefisien Persamaan Regresi Variabel $X_{1}$ dan $X_{2}$ terhadap $Y$ Coefficients $^{\mathrm{a}}$

\begin{tabular}{|c|c|c|c|c|c|c|}
\hline \multirow{2}{*}{\multicolumn{2}{|c|}{ Model }} & \multicolumn{2}{|c|}{$\begin{array}{c}\text { Unstandardized } \\
\text { Coefficients }\end{array}$} & \multirow{2}{*}{$\begin{array}{c}\begin{array}{c}\text { Standardized } \\
\text { Coefficients }\end{array} \\
\text { Beta }\end{array}$} & \multirow[b]{2}{*}{$\mathrm{t}$} & \multirow[b]{2}{*}{ Sig. } \\
\hline & & $\mathrm{B}$ & Std. Error & & & \\
\hline & (Constant) & 27,698 & 13,515 & & 2,049 & 043 \\
\hline & Integritas_Kepemimpinan_X $\mathrm{X}_{1}$ &, 617 &, 217 &, 317 & 2,847 &, 005 \\
\hline & Budaya_Organisasi_ $\mathrm{X}_{2}$ & ,433 & 264 &, 183 & 1,645 & , 103 \\
\hline
\end{tabular}

a. Dependent Variable: Efektivitas_Kerja_Guru_Y

Berdasarkan tabel hasil uji $t$ mengetahui persamaan regresi dapat dilihat diperoleh bahwa nilai $t_{\text {hitung }}$ variabel dari tabel di atas. Berdasarkan tabel tersebut integritas kepemimpinan kepala sekolah menunjukkan persamaan regresi linier $\left(\mathrm{X}_{1}\right)$ dan budaya organisasi sekolah $\left(\mathrm{X}_{2}\right)$ secara bersama-sama (simultan) memiliki nilai sebesar $p$-value $0,005<0,05$ artinya signifikan. Dengan demikian integritas kepemimpinan kepala sekolah $\left(\mathrm{X}_{1}\right)$ dan budaya organisasi sekolah $\left(\mathrm{X}_{2}\right)$ secara bersama-sama (simultan) berpengaruh terhadap efektivitas kerja guru (Y). Untuk pengaruh integritas kepemimpinan kepala sekolah dan budaya organisasi sekolah secara simultan (ganda) terhadap efektivitas kerja guru dapat dilihat dari nilai t pada tabel Coefficients dibawah ini dengan kriteria pengujian jika tingkat signifikansi lebih kecil dari 0,05. 
guru 0,839 dan 0,089 . Uji $\mathrm{F}$ untuk menguji hitung dengan nilai $\mathrm{F}$ tabel sebagai berikut: signifikan konstanta dan variabel dependen Jika nilai signifikansi $<0,05$, maka Ho (efektivitas kerja guru). Dari pengambilan ditolak artinya koefisien regresi signifikan, keputusan yaitu dengan membandingkan $\mathrm{F}$ dan sebaliknya.

Tabel 11: Signifikansi Pengaruh Variabel $X_{1}$ dan $X_{2}$ Secara Simultan Terhadap $Y$ ANOVA $^{\mathrm{a}}$

\begin{tabular}{|rl|r|r|r|r|r|}
\hline Model & & Sum of Squares & df & Mean Square & F & Sig. \\
\hline 1 & Regression & 3180,419 & 2 & 1590,210 & 12,907 & \multirow{2}{*}{$000^{\mathrm{b}}$} \\
& Residual & 12443,494 & 101 & 123,203 & & \\
& Total & 15623,913 & 103 & & & \\
\hline
\end{tabular}

a. Dependent Variable: Efektivitas_Kerja_Guru_Y

b. Predictors: (Constant), Budaya_Organisasi_X- $\mathrm{X}_{2}$, Integritas_Kepemimpinan_X adalah signifikan. Selanjutnya untuk

Berdasarkan tabel hasil uji anova atau F mengetahui seberapa besar pengaruh integritas test didapat $\mathrm{F}_{\text {hitung }}$ sebesar 12,907 dan kepemimpinan kepala sekolah dan budaya signifikansi $0,000<0,05$ sehingga $\mathrm{H}_{\mathrm{o}}$ ditolak organisasi sekolah secara simultan terhadap artinya pengaruh integritas kepemimpinan efektivitas kerja guru dapat dilihat dari hasil kepala sekolah dan budaya organisasi sekolah perhitungan koefesien determinasi pada tabel secara simultan terhadap efektivitas kerja guru dibawah ini:

Tabel 12

\section{Besaran Pengaruh Variabel $X_{1}$ dan $X_{2}$ Secara Simultan Terhadap $Y$} Model Summary

\begin{tabular}{|c|r|r|r|r|}
\hline Model & R & R Square & \multicolumn{1}{|c|}{$\begin{array}{c}\text { Adjusted R } \\
\text { Square }\end{array}$} & $\begin{array}{c}\text { Std. Error of the } \\
\text { Estimate }\end{array}$ \\
\hline 1 &, $451^{\mathrm{a}}$ &, 204 &, 188 & 11,100 \\
\hline
\end{tabular}

a. Predictors: (Constant), Budaya_Organisasi_X $\mathrm{X}_{2}$, Integritas_Kepemimpinan_ $\mathrm{X}_{1}$

Dari tabel di atas terlihat bahwa $R$ Square sekolah terhadap efektivitas kerja guru. sebesar 0,204, hal ini berarti bahwa 20,4\% Secara empirik, hasil penelitian ini efektivitas kerja guru dipengaruhi oleh menginformasikan: (1) terdapat pengaruh variabel integritas kepemimpinan kepala positif dan signifikan antara integritas sekolah dan budaya organisasi sekolah kepemimpinan kepala sekolah terhadap secara simultan, sedangkan sisanya 79,6\% efektivitas kerja guru, serta (2) besarnya dipengaruhi faktor lain yang tidak diteliti. kontribusi integritas kepemimpinan kepala

\section{Pembahasan}

Permasalahan yang ingin dijawab dalam penelitian ini adalah adakah pengaruh integritas kepemimpinan kepala sekolah terhadap efektivitas kerja guru ditunjukkan oleh hasil penelitian bahwa integritas kepemimpinan kepala sekolah yang terdiri dari dimensi: (1) Jujur; (2) 
Kredibel; (3) Transparan (Kouzes \& diterangkan oleh persamaan regresi $\hat{y}=$ Posner, 2007), membawa implikasi yang $38,888+0,832 \mathrm{X}_{1}$. Dengan persamaan signifikan terhadap efektivitas kerja guru yang meliputi dimensi: (1) Kemampuan menyesuaikan diri; (2) Kepuasan kerja; (3) Prestasi kerja Richard M Steers(1982). Pendekatan kepemimpinan integratif berfokus pada tujuan inti sekolah dan menyesuaikan kepemimpinan sekolah dengan tujuan sekolah, mengintegrasikan peran yang berbeda dan harapan, tetapi juga menekankan pemberdayaan semua pemangku kepentingan yang berbeda-beda (Huber, 2004a). Kepemimpinan terpadu mengintegrasikan tiga komponen yaitu: pertama, ada fokus dari tempat pendidikan yang dirumuskan dalam manajemen organisasi pendidikan. Mereka itu diantaranya adalah penerimaan terhadap stakeholder, dukungan dari otonomi mereka, dan kerjasama dalam pencapaian tujuan.

Namun demikian efektivitas kerja guru ini tidak hanya dipengaruhi oleh integritas kepemimpinan kepala sekolah saja, ada faktor lain (epsilon), selain dari budaya organisasi sekolah, yang juga berpengaruh, yang tidak dikaji dalam penelitian ini. Dengan demikian, hasil penelitian ini mengindikasikan bahwa semakin baik integritas kepemimpinan kepala sekolah, maka akan diikuti oleh semakin tingginya efektivitas kerja guru. Hal ini dapat regresi tersebut dapat diinterpretasikan bahwa jika integritas kepemimpinan kepala sekolah $\left(\mathrm{X}_{1}\right)$ dengan efektivitas kerja guru (Y) diukur dengan instrumen yang dikembangkan dalam penelitian ini, maka setiap perubahan skor integritas kepemimpinan kepala sekolah sebesar satu satuan dapat diestimasikan skor efektivitas kerja guru akan berubah 0,832 satuan pada arah yang sama.

Berdasarkan temuan empirik yang menunjukkan adanya pengaruh yang signifikan integritas kepemimpinan kepala sekolah dengan efektivitas kerja guru, maka hasil penelitian ini memberikan beberapa informasi, di antaranya: (1) integritas kepemimpinan kepala sekolah memberikan kontribusi yang berarti terhadap efektivitas kerja guru, (2) salah satu cara untuk meningkatkan efektivitas kerja guru adalah dengan meningkatkan integritas kepemimpinan kepala sekolah, serta (3) persentase kontribusi integritas kepemimpinan kepala sekolah terhadap efektivitas kerja guru adalah sebesar 18,2 $\%$, sementara sisanya dipengaruhi oleh variabel lain, selain variabel budaya organisasi sekolah, yang tidak dikaji dalam penelitian ini (epsilon).

Permasalahan yang ingin dijawab dalam penelitian ini adalah adakah 
pengaruh budaya organisasi sekolah berpengaruh, yang tidak dikaji dalam terhadap efektivitas kerja guru. Secara empirik, hasil penelitian ini penelitian ini.

menginformasikan: (1) terdapat pengaruh positif dan signifikan antara budaya organisasi sekolah terhadap efektivitas kerja guru, serta (2) besarnya kontribusi budaya organisasi sekolah terhadap efektivitas kerja guru ditunjukkan oleh hasil penelitian bahwa budaya organisasi sekolah yang terdiri dari dimensi: (1) Inisiatif Individual; (2) Toleransi terhadap tindakan berisiko; (3) Pengarahan; (4) Integrasi; (5) Dukungan Manajemen; (6) Kontrol Alat; (7) Identitas; (8) Sistem Imbalan; (9) Toleransi terhadap konflik; (10) Pola Komunikasi (Robbins, 2006), membawa implikasi yang signifikan terhadap efektivitas kerja guru yang meliputi dimensi: (1) Kemampuan menyesuaikan diri; (2) Kepuasan kerja; (3) Prestasi kerja Richard M Steers(1982). Menurut Owens (1995:167) bahwa "budaya organisasi sekolah adalah karaktersitik dari keseluruhan lingkungan di suatu sekolah yang terdiri dari dimensi kerjasama, semangat kerja, keterbukaan, melibatkan diri dalam setiap kegiatan dan tujuan". Namun demikian efektivitas kerja guru ini tidak hanya dipengaruhi oleh budaya organisasi sekolah saja, ada faktor lain (epsilon), selain dari integritas kepemimpinan kepala sekolah, yang juga

Dengan demikian, hasil penelitian ini mengindikasikan bahwa semakin baik budaya organisasi sekolah, maka akan diikuti oleh semakin tingginya efektivitas kerja guru. Hal ini dapat diterangkan oleh persamaan regresi $\hat{y}=42,453+0,885 X_{2}$. Dengan persamaan regresi tersebut dapat diinterpretasikan bahwa jika budaya organisasi sekolah $\left(\mathrm{X}_{2}\right)$ dengan efektivitas kerja guru (Y) diukur dengan instrumen yang dikembangkan dalam penelitian ini, maka setiap perubahan skor efektivitas kerja guru sebesar satu satuan dapat diestimasikan skor efektivitas kerja guru akan berubah 0,885 satuan pada arah yang sama.

Berdasarkan temuan empirik yang menunjukkan adanya pengaruh yang signifikan budaya organisasi sekolah dengan efektivitas kerja guru, maka hasil penelitian ini memberikan beberapa informasi, di antaranya: (1) budaya organisasi sekolah memberikan kontribusi yang berarti terhadap efektivitas kerja guru, (2) salah satu cara untuk meningkatkan efektivitas kerja guru adalah dengan meningkatkan budaya organisasi sekolah, serta (3) persentase kontribusi budaya organisasi sekolah terhadap efektivitas kerja guru adalah sebesar $14 \%$, sementara sisanya dipengaruhi oleh variabel lain, 
selain variabel integritas kepemimpinan kepala sekolah, yang tidak dikaji dalam penelitian ini (epsilon).

Permasalahan yang ingin dijawab dalam penelitian ini adalah adakah pengaruh integritas kepemimpinan kepala sekolah, dan budaya organisasi sekolah terhadap efektivitas kerja guru. Secara empirik, hasil penelitian in menginformasikan: (1) terdapat pengaruh positif dan signifikan antara integritas kepemimpinan kepala sekolah dan budaya organisasi sekolah secara simultan terhadap efektivitas kerja guru, serta (2) besarnya pengaruh integritas kepemimpinan kepala sekolah dan budaya organisasi sekolah secara simultan terhadap efektivitas kerja guru ditunjukkan oleh hasil penelitian bahwa integritas kepemimpinan kepala sekolah yang terdiri dari dimensi: (1) Jujur; (2) Kredibel; (3) Transparan (Kouzes \& Posner, 2007), serta budaya organisasi sekolah yang terdiri atas dimensi: Inisiatif Individual; (2) Toleransi terhadap tindakan berisiko; (3) Pengarahan; (4) Integrasi; (5) Dukungan Manajemen; (6) Kontrol Alat; (7) Identitas; (8) Sistem Imbalan; (9) Toleransi terhadap konflik; (10) Pola Komunikasi (Robbins, 2006), membawa implikasi yang signifikan terhadap efektivitas kerja guru yang meliputi dimensi: (1) Kemampuan menyesuaikan diri; (2) Kepuasan kerja; (3)
Prestasi kerja Richard M Steers(1982). Robbins (2001:20) menjelaskan bahwa efektivitas merujuk pada: the degree to which an organization realized its goals; the one going process of all going your organizational architecture with the market place. Its focus is on the organization to ensure that your mission, strategies, and goals synchronized and corsumer focused.

Namun demikian efektivitas kerja guru ini tidak hanya dipengaruhi oleh integritas kepemimpinan kepala sekolah, dan budaya organisasi sekolah saja, ada faktor lain (epsilon), yang juga berpengaruh, yang tidak dikaji dalam penelitian ini. Dengan demikian, hasil penelitian ini mengindikasikan bahwa semakin baik integritas kepemimpinan kepala sekolah, dan semakin bagus budaya organisasi sekolah, maka akan diikuti oleh semakin tingginya efektivitas kerja guru. Hal ini dapat diterangkan oleh persamaan regresi: $\widehat{Y}=27,698+0,617 X 1+0,433 X$. Dengan persamaan regresi tersebut dapat diinterpretasikan bahwa jika integritas kepemimpinan kepala sekolah $\left(\mathrm{X}_{1}\right)$, dan budaya organisasi sekolah $\left(\mathrm{X}_{2}\right)$ dengan efektivitas kerja guru (Y) diukur dengan instrumen yang dikembangkan dalam penelitian ini, maka setiap perubahan skor integritas kepemimpinan kepala sekolah dan budaya organisasi sekolah sebesar satu satuan dapat diestimasikan skor efektivitas 
kerja guru akan berubah 0,617 dan 0,433

satuan pada arah yang sama.

Berdasarkan temuan empirik yang menunjukkan adanya pengaruh yang signifikan integritas kepemimpinan kepala sekolah, dan budaya organisasi sekolah terhadap efektivitas kerja guru, maka hasil penelitian ini memberikan beberapa informasi, di antaranya: (1) integritas kepemimpinan kepala sekolah, dan budaya organisasi sekolah memberikan kontribusi yang berarti terhadap efektivitas kerja guru, (2) salah satu cara untuk meningkatkan efektivitas kerja guru adalah dengan meningkatkan integritas kepemimpinan kepala sekolah dan budaya organisasi sekolah. (3) persentase kontribusi yang diberikan oleh integritas kepemimpinan kepala sekolah dan budaya organisasi sekolah secara simultan terhadap efektivitas kerja guru adalah sebesar 20,4 \%, sementara sisanya dipengaruhi oleh variabel lain, yang tidak dikaji dalam penelitian ini.

\section{DAFTAR PUSTAKA}

Asiah, S. T. (2016). Efektivitas Kinerja Guru. TADBIR : Jurnal Manajemen Pendidikan Islam, Vol 4, No 2, Hal 1-11, Agustus 2016.

Baisary, R.P. (2013). "Pengaruh Integritas, Obyektivitas, Kerahasiaan, Kompetensi, dan Komitmen terhadap Kinerja Auditor pada Kantor Perwakilan Badan
PengawasanKeuangan dan Pembangunan (BPKP) Provinsi Sulawesi Tengah. eJurnal Katalogis, Vol 1, No 1, Januari 2013.

Cloud, H. (2006). Integrity: The Courage to Meet the Demand of Reality, How Six Essential Qualities Determine Your Success in Business. New York: Collins.

Mulyasa, E. (2005). Menjadi Guru Profesional. Menciptakan Pembelajaran Kreatif dan Menyenangkan. Bandung: Rosdakarya

Fitriah, N.(2018). Pengaruh Budaya Organisasi, Lingkungan Kerja Dan Kedisiplinan Terhadap Kinerja Guru (Studi Pada Smp Negeri 2 Sungai Ambawang). Jurnal Manajemen Update, Vol 7, No 2, 2018.

Habibi, B. (2013). Budaya Organisasi, Kompensasi, dan Kompetensi Pedagogik Serta Pengaruhnya terhadap Kinerja Guru, Cakrawala: Jurnal Pendidikan. Vol 7, No 1, 2013.

Huber, S. G. (2004a). Preparing School Leaders for the 21st century: An International Comparison of Development Programmes in 15 Countries. London: Routledge Falmer.

Kouzes, James M dan Posner, Barry Z. (2007). Leadership The Challenge: Tantangan Kepemimpinan. Alih Bahasa Wisnu Chandra Kristiaji. Edisi Ketiga. Jakarta: Erlangga

Owens, R. G. (1995). Organizational Behavior in Education. New York: Random House Inc.

Robbins, S. P. (2006). Organizational Behavior. Upper Saddle River, New Jersey, 07458 : Prentice Hall Inc. 
Steers, M.R. (1985). Efektifitas Organisasi Perusahaan. Jakarta: Erlangga

Subawa, I.M, dkk. (2015). Kontribusi Gaya Kepemimpinan Kepala Sekolah, Supervisi Akademik dan Motivasi Berprestasi Terhadap Kinerja Guru PNS di SMP Negeri di Kecamatan Gerokgak. e-Journal Program Pascasarjana Universitas Pendidikan Ganesha Program Studi Administrasi Pendidikan, Vol 6, No 1, Tahun 2015

Sunengsih. (2015). Hubungan Profesionalisme, Iklim Sekolah, dan Integrasi dengan Kinerja Guru optimal. Jurnal Manajemen. Vol 19, No 2, Juni 2015.

Suwardi, dkk. (2015). Pengaruh Loyalitas Terhadap Kinerja Guru SD. Jurnal Al- Azhar Indonesia Seri Humaniora, Vol .3, No. 1, Maret 2015

Wulandari, A.T.Y. (2016). Pengaruh Budaya organisasi Terhadap Kinerja Guru di SMK N 2 Ngawai Tahun 2014. EQUILIBRIUM: Jurnal Ilmiah Ekonomi dan Pembelajarannya, Vol 4, No 2, 2016. 